\title{
Spondyloepiphyseal dysplasia, Kimberley type
}

INSERM

\section{Source}

INSERM. (1999). Orphanet: an online rare disease and orphan drug data base.

Spondyloepiphyseal dysplasia, Kimberley type. ORPHA:93283

Spondyloepiphyseal dysplasia, Kimberley type (SEDK) is characterized by short stature and premature degenerative arthropathy. 